\title{
Constitución y crisis de las organizaciones republicanas de auxilio a los refugiados españoles. 1939-1942
}

\author{
FERnando Termis Soto
}

\section{INTRODUCCIÓN}

Considerada la guerra civil en el bando republicano como el prólogo de una confrontación más amplia entre fascismo y democracia, esta tesis cobraria aún más fuerza entre sus cuadros dirigentes al producirse el salto cualitativo en dicha confrontación que supone la segunda guerra mundial.

De otro lado era opinión prácticamente unánime entre ellos que en la victoria del ejército franquista habia tenido una responsabilidad esencial la participación directa de fuerzas militares italianas y alemanas, así como su auxilio material en créditos y suministros militares, de modo que se identificaba la victoria de los sublevados con una primera victoria parcial, en el terreno bélico, del Eje.

Por estas razones, muchos republicanos españoles retomaron las armas en septiembre de 1939, para defender Francia en lo que ellos suponian era la continuación de la misma guerra, y en este sentido considerarian una victoria de los aliados como una victoria propia que inmediatamente habria de conducir a «reajustar las cuentas" en la propia España.

Pero el oportunismo político de Franco, y la desintegración que habian sufrido las instituciones republicanas por causa de las divisiones intestinas fueron, entre otras, las razones que hicieron discurrir los acontecimientos posteriores por vias bien distintas a las deseadas por los republicanos. 
En este sentido, se perfilan dos posiciones distintas entre los exiliados. Por una parte, los que como Negrin, Alvarez del Vayo, Fernando de los Ríos, etc., consideran tarea primordial la reconquista de la República con el concurso de los aliados, que eventualmente habrian de reconocer los errores cometidos en el pasado. De otra, los que como Indalecio Prieto auguran una larga prevalencia del franquismo en España, considerando consiguientemente que los intereses de los exiliados pasan en primer lugar por conseguir una repatriación a España con todas las garantias, y vista la imposibilidad de conseguir este propósito, integrarse de la mejor manera posible en cada uno de los paises de recepción -básicamente de América latina-. Las organizaciones dirigidas por partidarios de una u otra opción serán, respectivamente, el SERE (Servicio de Evacuación de los Republicanos Españoles) y la JARE (Junta de Auxilio a los Republicanos Españoles), durante el primer trienio del exilio, cuando se perfilan las cuestiones que habrán de determinar la estrategia politica de los dirigentes republicanos de cada fracción en el futuro inmediato.

En el terreno de lo práctico, cuando en marzo de 1939 las instituciones republicanas subsistentes se instalan en Francia, cerca de medio millón de republicanos españoles, civiles y militares, se encuentran en ese pais o en sus dependencias norteafricanas, internados en los campos de concentración de Argelés, Le Vernet, St. Cyprien, Le Barcarés, etc., rodeados de alambradas y vigilados por gendarmes y tropas coloniales.

Semejante masa de refugiados habria de plantear problemas humanitarios y políticos, problemas en los que estarian involucrados los gobiernos de Francia, de la ya prácticamente inexistente España republicana, y el gobierno franquista que quedaba en Burgos vencedor de la guerra civil. De esta manera, los refugiados se convierten en punto central de las relaciones franco-españolas.

El exilio español a que da lugar la guerra civil, cuenta con ciertas peculiaridades que le diferencian de otras diásporas por las que han tenido que pasar los españoles en momentos anteriores de su historia ${ }^{1}$ siendo de peculiar relevancia el hecho de ser un exilio perfectamente encuadrado, o dicho de otro modo, que a la masa de exiliados en gran parte y vinculada a una u otra organización -partido o sindicato-, se superpone un Estado, aún reconocido como único representante de España por varios paises, como México o la Unión Soviética, pero también conservando una relativa influencia ante el gobierno francés, que en febrero ya ha re-

Sobre los exilios de los españoles a lo largo de su historia: Abellan, J. L. (dir.), ob. cit, especialmente su tomo I. 
conocido a Burgos, juntamente con Gran Bretaña. Este hecho tendrá importantes consecuencias para los refugiados españoles, ya que permitirá a las instituciones republicanas exiliadas conservar un margen de maniobra suficiente durante unos meses como para emprender las labores de evacuación hacia Latinoamérica, en principio a través del SERE y con la solidaridad del gobierno mexicano, justo hasta el momento en que la política internacional, y en particular el pacto germano-soviético hagan inclinarse al gobierno francés en contra de este organismo y del gobierno que lo sustenta.

En tales circunstancias, no está muy lejos de la realidad concebir la situación de los exiliados republicanos como lo hace un documento confidencial de la embajada española en París ${ }^{2}$, como ciudadanos de un Estado perfectamente estructurado en ministerios, Cortes elegidas por sufragio universal, presupuesto, relaciones internacionales... pero sin un metro cuadrado de territorio sobre el que asentarse.

El sentido de la conservación de dicho Estado, aún a pesar de su degradación y sus escisiones, reside en la esperanza de convertirse en sustituto del Estado franquista, toda vez que es el único acorde con la legalidad republicana, y entre tanto, servir como centro de coordinación del socorro moral y material a los refugiados españoles, siguiendo una politica de subsidios, de evacuación, o de incorporación a la sociedad y el sistema productivo francés, legalizando su situación jurídica. A la mejor consecución de estos fines, adecuarán su actuación las organizaciones de los republicanos españoles, con diferentes resultados dadas las circunstancias en que se veian inmersos.

\section{CONSTITUCIÓN Y ACTIVIDADES DEL SERE}

Prescindiendo de las diferentes organizaciones internacionales de auxilio a los republicanos que actuaron en conexión con las españolas, la primera que se organiza es el SERE, a instancias del gobierno republicano (vid. notas $n^{\circ} 3$ y 4 ). En su aparición tendrá un relevante papel el embajador de México en Paris, señor Bassols.

En estas fechas, los Estados Unidos Mexicanos es uno de los pocos paises que aún reconocen la legalidad republicana y a su gobierno. Ha-

\footnotetext{
${ }^{2}$ Archivo General de la Administración-Asuntos Exteriores (en adelante AGA-AAEE). Caja 11.257, carpeta 1, exp. 006-134, s/f.
} 
biendo tenido a lo largo de la guerra una abierta actuación de apoyo al mismo por la afinidad politica de su presidente, Lázaro Cárdenas (del Partido Revolucionario Mexicano, coalición de comunistas, liberales radicales, Confederación de Trabajadores Mexicanos y Confederación Nacional de Campesinos), cuando el gobierno republicano español se instala en Paris tendrá en la embajada mexicana y en su titular un eficaz mediador ante el gobierno francés, que oficialmente no reconoce ya más gobierno que el de Franco, y que por añadidura ha firmado el 25 de febrero en Burgos unos acuerdos que habrán de mediatizar su relación con el gobierno Negrín y las organizaciones de los exiliados.

Este embajador, en contacto con el gobierno exiliado, y ante la dificil situación en que se encuentran los internados en los campos, viajará a México con un proyecto de evacuación que expondrá a Cárdenas, quien por lo demás ya en diciembre de 1938, habia mantenido contactos con Negrin al objeto de acordar un contingente de emigrados en número de 60.000 , preservándose el secreto de los mismos para no desmoralizar aún más a las tropas republicanas cuando comienza la ofensiva franquista sobre Cataluña ${ }^{3}$.

A resultas de estas gestiones, con el visto bueno de Cárdenas y del ministro francés del Interior, Sarraut, se organiza en París el SERE ${ }^{4}$, del que queda como presidente Pablo de Azcárate, director general Ossorio Tafall (sustituido posteriormente por Viana), y secretario general I. Mantecón. En este organismo estarán representados Izquierda Republicana (Baeza Medina), PSOE (Otero), CNT (Mariano R. Vázquez), UGT (Amaro del Rosal), PNV (Jáuregui), PCE (Mije), y Esquerra Republicana (Ayguadé). Es de señalar además que la dirección del SERE estuvo siempre en manos de Izquierda Republicana, con la probable intención de restar argumentos a quienes la calificarán de instrumento comunista, como ocurriria en la propaganda del sector en torno a Prieto y la JARE.

En breve, la organización se extiende por Francia, apareciendo delegaciones en las ciudades del Mediodia francés, en torno a las cuales es-

\footnotetext{
${ }^{3}$ De acuerdo con J.M. Valle (Ob. cit, págs. 45-46), la primera iniciativa en este sentido corresponderia a Gordón Ordás, quien en su calidad de embajador de la República en México, y en previsión de una derrota final de las armas republicanas en la guerra, en abril de 1938 ya trató con Cárdenas sobre la eventualidad de recibir en ese pais un gran contingente de refugiados españoles.

${ }^{4}$ Existen antecedentes del SERE desde 1937, creado entonces para gestionar la evacuación de la zona cantábrica a requerimiento del gobierno francés. VALLE, J. M., Ob. cit., pág. 33.
} 
tán ubicados los campos: Limoges, Marsella, Perpiñán, Toulouse ${ }^{5}$, etc. Sus empleados administrativos saldrán de las federaciones de banca de los sindicatos, y del ministerio de Hacienda republicano, incluido el ministro Méndez Aspe.

La primera labor que emprende el SERE una vez que se legaliza su existencia ante el ministerio del Interior francés, consiste en realizar un censo de los refugiados internados en los campos de concentración, con una valoración de su situación familiar y personal al objeto de establecer las prioridades de emigración: en este sentido, se considerarán "emigrables", en primer lugar los cuadros políticos y sindicales con responsabilidad en las diferentes organizaciones representadas ante el SERE, siendo esta condición incompatible con la percepción de cualquier tipo de subsidio, descartándose por añadidura el relativamente escaso número de refugiados dispuestos a repatriarse voluntariamente, número que no aumentará significativamente a pesar de las presiones francesas, que en mayo de 1939 incluirán la incorporación forzosa a batallones de trabajo o el alistamiento.

Este modo de proceder se explica por la imposibilidad de hacer frente a los cuantiosos gastos que hubiera supuesto la evacuación de tantos miles de refugiados con los limitados recursos a disposición del gobierno Negrin y del SERE, cifrados en 250 millones de francos franceses antiguos ${ }^{6}$, más lo que rendian los valores invertidos y bajo su control en el "Banque National d'Europe du Nord", controlado por la Unión Soviética, y otros bancos. De ahi la justificación de la politica selectiva respecto a los "emigrables", que sólo tuvo apoyos parciales, entre los que destaca el prestado por el "Comité Británico de Ayuda", inspirado por la duquesa de Atholl, que subvencionó un contingente de mil refugiados en la primera expedición hacia México.

Cabe aqui hacer mención además al hecho de que la pérdida del control de los recursos embarcados en el Vita por parte del SERE, consecuencia del enfrentamiento Prieto-Negrín, vino a sustraer una importante fuente de recursos que agravó su situación financiera, de manera que sólo pudo ser ésta sostenida hasta mediados de 1941, cuando se procede a su disoiución.

\footnotetext{
5 Toulouse era el principal centro de concentración y actividad de los refugiados españoles en el sur de Francia. Esta actividad llega incluso a la creación de una «oficina consular» del SERE para la evacuación hacia América, y una red republicana de espionaje. AGA-AAEE. Caja 11.287, carpeta 1, exp. 0006-82 de 14-IV-39.

${ }^{6}$ Cfr. TCACH, César, ob. cit., pág. 27.
} 
EI SERE no realizaba por si la selección de los susceptibles de evacuación, sino que a partir de los considerados "emigrables", asignaba una proporción a cada una de las organizaciones en él representadas, de manera que tras largas discusiones en las que finalmente hubo de recurrirse al arbitraje de Azcárate, la distribución de la primera expedición colectiva, realizada en el Sinaia el 25 de Mayo de 1939, quedó del siguiente modo: marxistas (UGT, PSOE, PCE) $38 \%$; republicanos (IR, UR, ERC) $33 \%$; libertarios (CNT, FAl) $24 \%$; sin partido $5 \%$, siendo posteriormente, el 26 de junio, desglosada definitivamente para ulteriores expediciones, con la siguiente atribución de porcentajes ${ }^{7}$ : IR, $6 \%$; PSOE, $13 \%$; UGT, $22 \%$; PCE, $11 \%$; PNV, $3 \%$; ANV, $3 \%$; CNT, $18 \%$; FAI, $4 \%$; ERC, $5 \%$; AC, $2 \%$; UR, $4 \%$; PSUC, $5 \%$; sin partido, $3 \%$.

De estas cifras, cabe señalar la importancia que se concede a la militancia socialista y comunista, habida cuenta de la identidad de militancia en el PSOE y la UGT (es decir, que el militante del partido lo es necesariamente del sindicato) y el hecho de que están excluidos de facto los militantes no identificados con el negrinismo. Respecto a los comunistas, vale hacer semejante consideración, después de la unificación de la CGTU y la UGT, añadiéndose el hecho de ver su representatividad desdoblada entre el PCE y el PSUC. Es remarcable también la importante proporción atribuida a los republicanos, habida cuenta de que nunca fue ninguno de sus partidos organizaciones de masas como lo pudieran ser los propios sindicatos.

El primer destino de los evacuados será México, cumpliendo así con lo acordado entre Cárdenas y Negrín a través de Gordón Ordás. Pero a medida que avanza el año de 1939, varios países latinoamericanos se prestan a recibir refugiados españoles. Asi lo hacen Chile, donde por mediación de Pablo Neruda sale de Burdeos el 4 de agosto un contingente de algo más de 3.000 refugiados, del que expresamente el gobierno chileno ha excluido a los anarquistas, por lo que será repartido su porcentaje ${ }^{8}$. Esta exclusión de los elementos libertarios de los contingentes de evacuación, bien por decisión de las autoridades de los paises de recepción, o bien por carecer de las poderosas influencias de otras organizaciones, fue la causa de que a lo largo de la guerra mundial el mayor número de los mismos se encontrara en la invadida Francia, y que por contra, la emigración anarquista en México fuera relativamente reducida.

Del Rosal, Amaro, ob. cit., pág. 160.

${ }^{8}$ UGT: $40 \%$; PSOE, PCE y republicanos: $20 \%$ respectivamente. 
Argentina, gracias a la iniciativa de su presidente Irigoyen, también se presta a aceptar a varios centenares de inmigrantes, con la condición de que fuesen vascos, al igual que Venezuela. A estos lugares se lleva adelante la evacuación a través del "Comité pro-Inmigración Vasca". Otros destinos, producto de iniciativas particulares fueron los Estados Unidos, Costa Rica, Unión Soviética, etc.

Caso especial es el de la República Dominicana. Bajo la dictadura de Leónidas Trujillo, varios miles de refugiados serían aceptados con el objetivo de potenciar la colonización del pais, al mismo tiempo que su economia. Tras varias expediciones de refugiados, se demuestra la incapacidad de la economía dominicana para absorber el excedente de mano de obra que generan cerca de 4.000 recién llegados, lo que obliga al SERE a realizar costosas inversiones en proyectos de colonización i: rior sin resultados apreciables. Esto, unido al carácter político de la emigración, hace que Trujillo opte por no aceptar un último contingente ya embarcado, que será forzado a dirigirse a Martinica, y desde allí, a México, donde podrán desembarcar en un puerto atlántico meridional. Forzados por las circunstancias, los refugiados en la República Dominicana, salvo excepciones, abandonarán también el pais para dirigirse a Cuba, México o Panamá, donde son aceptados en pequeños contingentes a lo largo de 1940.

Según A. del Rosal, los contingentes evacuados de Francia y del norte de Africa por el SERE, son los que se dan a continuación ":

\begin{tabular}{cllr}
\hline FECHA & \multicolumn{1}{c}{ NOMBRE } & DESTINO & $\begin{array}{c}\text { NUMERO } \\
\text { EMIGRANTES }\end{array}$ \\
\hline $10-\mathrm{V}-39$ & Siboney & México & 30 \\
$17-\mathrm{V}$ & México & México & 8 \\
$19-\mathrm{V}$ & Iseri & México & 7 \\
$24-\mathrm{V}$ & Orizaba & México & 16 \\
$25-\mathrm{V}$ & Sinaia & México & 1.620 \\
$1-\mathrm{VI}$ & Flandre & México & 312 \\
$1 / \mathrm{V} 1$ & Siboney & México & 23 \\
$13-\mathrm{VI}$ & Ipanema & México & 1.000 \\
$13-\mathrm{VI}$ & Orinoco & México & 41 \\
$28-\mathrm{VI}$ & México & México & 9 \\
$4-\mathrm{VII}$ & Lergan & México & 18 \\
$5-\mathrm{VII}$ & Monterrey & México & 6 \\
& & & \\
& & &
\end{tabular}




\begin{tabular}{cllr}
\hline FECHA & \multicolumn{1}{c}{ NOMBRE } & \multicolumn{1}{c}{ DESTINO } & $\begin{array}{r}\text { NUMERO } \\
\text { EMIGRANTES }\end{array}$ \\
\hline $7-V I I$ & Ipanema & México & 998 \\
12/VIII & Siboney & México & 19 \\
13-VII & Méxique & México & 2.091 \\
19-VII & México & México & 1 \\
19-VII & Iberia & México & 42 \\
$4-V I I I$ & Winnipeg & Chile & 2.025 \\
$7-I X$ & Flandes & R. Dominicana & 300 \\
19-XII & Lassalle & R. Dominicana & 710 \\
10-I-40 & Cuba & R. Dominicana & 800 \\
$23-I I$ & Lasalle & R. Dominicana & 600 \\
$22-I V$ & Lassalle & R. Dominicana & 1.500 \\
$16-V I$ & Cuba & R. Dominicana & 540 \\
\hline
\end{tabular}

Hubo además muchas otras expediciones con diversos destinos en barcos de línea regular.

Siendo no obstante las actividades de impulso a la emigración las más importantes llevadas a cabo por el SERE, no faltaron por el volumen de la emigración y la limitación de los recursos las destinadas a conseguir la inserción en el sistema productivo francés, y con ella su autosuficiencia. Desde el punto de vista del SERE, la demanda de mano de obra cualificada y sin cualificar requerida por las perspectivas de una guerra en ciernes, hizo pensar en un principio en la viabilidad de esta politica, y en tal sentido se presentaron al gobierno francés proyectos de colonización agricola e incorporación de trabajadores industriales a la producción, respaldados por expertos franceses e internacionales, reunidos en congresos celebrados al efecto, como los de París de 10 y 11 de junio y de 15 y 16 de julio de 1939.

Frente a estas propuestas, el gobierno francés miró más a su propio interés que a una eventual politica de asistencia e inserción generalizada. A los refugiados españoles que a partir de mayo de 1939 rehúsan la repatriación, opta por incorporarlos a los militarizados batallones de trabajo, destinados generalmente a la construcción de obras públicas en las colonias norteafricanas, mientras otros más afortunados son destinados a la industria bélica en aprovechamiento de su cualificación. Otra porción, es instada a alistarse en la Legión Extranjera ${ }^{10}$. De resultas de todo lo

${ }^{10}$ AGA-AAEE. Caja 11.287, carpeta $3 .^{\circ}$. Despacho del embajador en Paris al ministro de Asuntos Exteriores de 16-V-1939. 
anterior, estadísticas del SERE de abril de 1940 muestran que son 15.000 los enrolados en la Legión Extranjera; 70.000 los incorporados a batallones de trabajadores; 40.000 los empleados en fábricas y talleres metalúrgicos, y 6.000 los ancianos, mujeres y niños que quedan en campos de concentración ${ }^{11}$.

Capitulo aparte es el de los militares profesionales republicanos, quienes en buena medida se ofrecieron para integrarse en el ejército francés, lo que no ocurrió por la sustancial reducción de graduación que se les quiso imponer.

\section{LAS ACTIVIDADES DE INDALECIO PRIETO Y DE LA JARE}

Ya antes de la finalización de la guerra civil, en el PSOE y en la UGT, fuerzas de influencia mayoritaria en el Frente Popular, se habian puesto de manifiesto las profundas divisiones internas que, lejos de superarse en el exilio, implicaron la división del mismo en prietistas y negrinistas, lo que debilitó notablemente la influencia de las organizaciones de cara a los propios refugiados pero sobre todo de cara a las potencias internacionales de las que se esperaba el apoyo necesario para derrotar en España al franquismo.

Para entender las razones que llevaron al exilio a la división entre pro y antigubernamentales, hay que retrotraerse a mayo de 1937, cuando cae el gobierno Largo Caballero, sustituyéndolo el primero de Negrín, con Prieto en el ministerio de Defensa. Ésto, unido a la ofensiva lanzada en el terreno sindical contra la hegemonia de la izquierda socialista encabezada por Largo Caballero, en la que se unen comunistas, moderados de Besteiro y negrinistas, le supone la primera defección de un sector de amplia influencia en el campo socialista -y por ende frentepopulista-, si bien consigue que la UGT pase a estar controlada por una Comisión Ejecutiva afecta al nuevo gobierno ${ }^{12}$.

\footnotetext{
1 AGA-AAEE. Caja 11.287, carpeta 3. ${ }^{\text {. }}$ Despacho del embajador en París al ministro de Asuntos Exteriores de 9-IV-1940.

12 Dicha CE estará compuesta por González Peña (presidente), E. Dominguez (vicepresidente), Rodríguez Vega (secretario general), A. Genova (vocal), A. del Rosal (secretario adjunto), F. Pretel (tesorero), C. Lombardia (vocal), D. Anguiano (vocal), C. Garcia (vocal) y A. Pérez (vocal). R. Zabalza, J. Diaz Alor, Pascual Tomás y C. Hernández Zancajo, vocales del sector caballerista, no participaron de hecho en la CE. Sobre las circunstancias en que se produce este cambio, ver: BorRas, J., ob. cit., págs. 89-90
} 
La segunda defección de que es objeto el gobierno del doctor Negrin comienza con la retirada de Prieto del gobierno el 29 de marzo de 1938, tras un informe sobre la situación militar abiertamente derrotista, que le vale la destitución. La crisis se cierra con la asunción por el presidente del gobierno de la cartera de Defensa, pero con ello comienza la irreductible enemistad de Prieto hacia Negrín, y la adopción de aquél de firmes actitudes anticomunistas. El segundo gobierno Negrín consigue aún ampliar su base social, al incluir un ministro de la CNT, gobierno que por to demás recibirá múltiples mociones de confianza por parte de la Diputación Permanente de las Cortes, sobre las cuales una vez en el exilio, Negrin fundamentará sus títulos de legitimidad.

Prieto, sin embargo, no hace sino sumarse a una fuerte tendencia anticomunista que hacia ya tiempo se habia venido organizando en el campo republicano, y que con participación de los caballeristas y de los besteiristas del PSOE y de la UGT se manifestará en el golpe del coronel Casado y la creación del Consejo Nacional de Defensa (en el que está integrado el propio Besteiro en calidad de presidente), que niega la autoridad del gobierno. Con esta acción, en la madrugada del 5 al 6 de marzo de 1939 se puede considerar rota de hecho la unidad del PSOE y de la UGT. Ésta es la definitiva defección que sufre el gobierno Negrín procedente del propio partido del presidente (prescindiendo por tanto de las de Ayguadé e Irujo, de ERC y PNV respectivamente, que tuvieron lugar en agosto de 1938). En lo sucesivo, Negrín sólo contará con el apoyo de un sector de su propio partido y de los comunistas, en tanto los republicanos pasan de hecho a la oposición al inscribirse en el frente anticomunista que se va a presentar ante los aliados como alternativa al franquismo en España. E incluso los comunistas marcarán las distancias con el gobierno en el exilio a partir del viraje político del Komintern y de la Unión Soviética en 1940.

Prieto por contra, encabeza un sector socialista en ascenso, al aglutinar en torno a si a los moderados en el exilio - en ausencia de Besteiro, que queda preso en Madrid-, asi como a los divididos caballeristas, ya que si bien Araquistain y Largo Caballero son partidarios de combatir tanto a comunistas como a prietistas, notables partidarios suyos como Hernández Zancajo, Wenceslao Carrillo y Pascual Tomás son partidarios de unirse a Prieto para destruir politicamente a Negrin. De hecho, la inhibición de Largo Caballero permitirá a Prieto conseguir la destitución de $\mathrm{Ne}$ grín el 27 de julio de 1939.

Esta cuestión, se enmarca dentro de una viva polémica en los medios del exilio republicano, acerca de la legitimidad de sus instituciones una vez que, cruzada la frontera francesa, no ejercen jurisdicción real sobre 
parte alguna del territorio español. En los meses subsiguientes a la finalización de la guerra en España, tienen lugar en Paris varias reuniones de la Diputación Permanente, en las que se ventila esta cuestión de la legitimidad — particularmente en la de 31 de marzo_, llegándose por fin a un acuerdo de mutuo reconocimiento entre el gobierno y la Diputación, subsistente hasta el momento de la destitución ${ }^{13}$.

A finales de marzo, Prieto se habia hecho cargo en México del cargamento del Vita, "por imperativo de una alta jerarquia mexicana", con el beneplácito de Gordón Ordás, José Giral, Augusto Barcia y Sebastián Pozas ${ }^{14}$. Este barco habia sido adquirido recientemente por el gobierno republicano con el objeto de evacuar bienes sacados de España hacia México, quedando sin embargo anclado en el puerto de Veracruz. En cuanto a su cargamento, que constituía una parte nada desdeñable de los recursos de que podia disponer el gobierno, fue entregado a Prieto por el encargado de su custodia, Enrique Puente, y con estos recursos dispuso aquél de la base económica necesaria para constituir la JARE (Junta de Auxilio a los Republicanos Españoles). Desde el momento en que accede a ellos, se titula como único responsable de su administración y custodia, momento en que regresa a Francia ${ }^{15}$ para organizar la oposición politica a Negrín.

El triunfo político de Prieto, no habria de esperar mucho, pues se produce en la reunión de la Diputación Permanente de las Cortes el 26 y el. 27 de julio, en la que se acuerda la marginación del gobierno republicano, al mismo tiempo que se autoproclama como la única representación de la República, y estableciéndose una nueva organización del SERE, bajo el nuevo nombre de JARE, con una nueva dirección en la que Nicolau d'Olwer ocupa la presidencia, Esplá la secretaria general, y en representación de las distintas organizaciones, en calidad de consejeros, Andreu (Esquerra), Valentín (UR), Palomo (IR), Prieto (PSOE), Peiró (CNT) y A. Fernández (UGT).

Las razones por las que se adopta esta decisión, después de las múltiples mociones de confianza dadas al gobierno, se expresan en la afirmación de que “... no es posible reformarle ni cambiarle y nadie osará suponerlo permanente contra la voluntad de sectores políticos y parla-

\footnotetext{
13 Vèase Valle, J. M., ob. cit, págs. 18 y ss.

${ }^{14}$ La gestión de Prieto en torno a esta cuestión, fue expresamente aprobada por la Diputación Permanente y la Comisión Ejecutiva del PSOE. Véase VALLE, J. M. del, ob. cit., págs. 36-40, y Borras, J., ob. cit., págs. 86-88.

${ }_{15}$ Previamente habia estado en Chile, como representante del gobierno en la toma de posesión del presidente Aguirre Cerdá, desde donde se trasladaria a México.
} 
mentarios que le dieron vida» ${ }^{16}$. La Diputación Permanente, hace así buena una supuesta facultad de destituir al gobierno, facultad que habia sido señalada por Martínez Barrio en ocasiones anteriores.

Pero hay ciertos aspectos de esta decisión de la Diputación Permanente que han permitido señalar serias objeciones sobre su legalidad. De acuerdo con diversos autores ${ }^{17}$, la destitución del gobierno es ilegal, dado que la Diputación Permanente se extralimita en sus atribuciones. De acuerdo con el articulo 64 de la constitución de 1931, era necesario tener un mínimo de 50 votos para presentar una moción de censura, debiendo luego ésta recibir el apoyo de la mayoria de las Cortes para cesar al presidente del gobierno y sus ministros. De otro lado, el grupo parlamentario socialista que reúne Prieto, se forma ignorando los estatutos del PSOE, a su Comisión Ejecutiva, y a la dirección de la minoría socialista en la Diputación, además de a ciertos diputados como el propio Negrín, Álvarez del Vayo, Lamoneda, etc. Por añadidura, once de estos 17 diputados, estaban sancionados por su ausencia de Figueras.

Pero a pesar de la aparente ilegalidad, la Diputación Permanente aprueba estas iniciativas con los votos favorables de parte de los socialistas, Unión Republicana, Izquierda Republicana, la abstención del PNV y Portela Valladares, el voto en contra del PCE, y las reservas de Valera (UR) y Miñana (IR).

Las consecuencias de estos acuerdos es consolidar y formalizar las divisiones de los republicanos, pues el gobierno los considerará facciosos y por tanto nulos, de modo que desde estas fechas, y en lo sucesivo hasta 1943, el exilio estará escindido entre partidarios del SERE y de la JARE, o lo que es lo mismo, partidarios del gobierno y de la Diputación Permanente. Éste es pues el arranque de la organización dual del exilio, producto del conflicto existente en el seno del socialismo, y de la hostilidad de que se habian hecho acreedores los comunistas a lo largo de la guerra civil por parte de los otros sectores republicanos.

Las actividades de la JARE toman desde su constitución una orientación distinta de la del SERE, en la que tiene una menor incidencia la evacuación desde Francia y el norte de África hacia América. De hecho el $90 \%$ de los evacuados lo son a través del SERE, mediante una política selectiva que explica la composición mayoritariamente negrinista del exilio socialista mexicano.

\footnotetext{
${ }^{16}$ VALLE, J. M. del, ob. cit., pág. 44.

17 TCACH, C., ob. cit., pág. 27; HeINE, H., ob. cit., pág. 31; del Rosal, A., ob. cit., págs. 188 y ss
} 
A este respecto, hay que hacer notar el hecho de que tanto el SERE como la JARE, no dejaron de utilizar, en mayor o menor medida, la posibilidad de influir tan gravemente en la situación personal de los refugiados -al tener la facultad de conceder o denegar subsidios, de decidir la composición de los pasajes hacia América, etc.,- para ganar lealtades entre los mismos. Prácticas que fueron objeto de reciprocas campañas de denuncia, y que sólo tuvieron la virtualidad de hacer más profundo el foso que separaba a las distintas fracciones del exilio.

Prieto se planteará la posibilidad de un retorno de los exiliados a España y la renuncia a las represalias, a cambio de la devolución al Estado español de los recursos en su poder, llegando a mantener conversaciones en tal sentido con Lequerica, a la sazón embajador de España en París, quien se mostró favorable a tal opción. Pero hubo de ser abandonada en espera de hacer plenamente efectivos los acuerdos Jordana-Berard, a través de los cuales Franco y Serrano Suñer esperaban obtener una completa satisfacción de sus demandas en lo referente a los bienes exportados por los republicanos en su huida ${ }^{18}$. Es por esto por lo que los fletes de expediciones hacia México costeados por la JARE, no comenzaron hasta octubre de 1941, a pesar de las dificiles condiciones en que se encuentran los refugiados en Francia, agravadas por la multitudinaria afluencia de refugiados provenientes de toda Europa a partir de septiembre de $1939^{19}$. Al acercarse los alemanes a Paris, Prieto envia a Cárdenas una carta con fecha 17 de junio de 1940 donde le suplica la organización del flete de barcos; Cárdenas por su parte, todo lo que puede hacer en tan poco tiempo es decretar la admisión de todos los españoles refugiados en Francia, otorgándoles protección diplomática el 23 de junio, lo que no bastó para impedir la deportación a España por la Gestapo y el fusilamiento de Peiró, Zugazagoitia y Companys.

Las expediciones colectivas que llega a organizar la JARE son tres, comprendidas en los años 1941 y 1942, últimas del ciclo de evacuación colectiva. Las fechas en que se llevan a cabo, son el 30 de octubre de 1941, el 14 de abril de 1942, y la última en octubre del mismo año. Posteriormente permanece activa una emigración de carácter individual, coordinada a través de la Federación de Organizaciones de Auxilio a los Republicanos Españoles (FOARE).

\footnotetext{
18 AGA-AAEE. Caja 11.287, carpeta 3. . Despacho del subsecretario de Asuntos Exteriores al embajador en Paris de 6-IX-39, para la estimación de los bienes controlados por Prieto.

19 Archivo de Amaro del Rosal Díaz (AARD) 271-3/00019. Carta de Álvarez del Vayo a Amaro del Rosal de 28-VI-40.
} 
La actividad de la JARE en Francia entre julio y septiembre de 1939 - fecha en que la organización se traslada a México-, fue más fácil que la del SERE, por cuanto contó desde su aparición con el beneplácito de las autoridades francesas en detrimento de éste ${ }^{20}$, por su condena del pacto germano-soviético. Este pacto provoca una reacción anticomunista en el gobierno francés traducida en la represión de las organizaciones comunistas o supuestamente filocomunistas (entre ellas el SERE), en tanto que la inspirada por Prieto no es molestada. No obstante a lo largo de 1941 y 1942, la JARE encuentra cada vez más dificil controlar sus fondos mexicanos, haciéndose imprescindible un organismo único de auxilio a los refugiados. Por esta razón, en diciembre de 1942 el gobierno de Ávila Camacho -sucesor de Cárdenas en 1940- decide la incautación de los bienes de la Junta, cuya administración pasa a una comisión gubernativa, lo que significa el fin de las disensiones, pero también el fin de la propia JARE.

\section{EL SERE Y LA JARE ENTRE LAS RELACIONES HISPANO- FRANCESAS}

La enorme masa de refugiados españoles, así como las organizaciones en que estaban integrados y las que realizaban funciones de auxilio, sería uno de los asuntos de mayor relevancia en las relaciones francoespañolas desde el fin de la guerra civil, hasta que la guerra mundial impone un nuevo sentido a las mismas.

Las bases para el entendimiento entre ambos Estados, se habian echado ya el 25 de febrero de 1939, cuando con motivo del reconocimiento del gobierno de Burgos por Francia, se firmaron los pactos Jordana-Bérard, cuyo cumplimiento se preveía que fuese el comienzo de una política "de buena vecindad". Ahora bien, unos intereses y unos objetivos internacionales divergentes, la interpretación dispar de los mismos, y el temor francés a un alineamiento español junto a Alemania e Italia en la próxima guerra, fueron las razones que impidieron su total cumplimiento, lo que no dejó de redundar durante cierto tiempo en beneficio de los republicanos exiliados.

20 AGA-AAEE. Caja 11.287, carpeta 3. . Despacho del SIPM de 28 de agosto de 1939 a los ministros de Asuntos Exteriores, Gobernación y subsecretario de la Presidencia del Gobierno. 
Las causas de que esto fuese asi, estriban en que el tema de los refugiados es elemento primordial y baza politica de la cual ambas partes procurarán extraer beneficios. Por parte francesa se pensaba que la amenaza de una deportación masiva de individuos hostiles al régimen, que por lo demás lo que menos necesitaba eran más bocas que alimentar, podria constituir un sólido elemento de presión para contrarrestar eventuales amenazas procedentes de su frontera meridional. Por parte española, se consideraba el tema de los refugiados como una garantía del cumplimiento del resto de lo pactado, referido esencialmente a la devolución de bienes españoles evacuados durante la guerra, el alejamiento de la frontera de los refugiados, y la represión de las actividades "antiespañolas". De este modo, se esperaba imponer el ritmo de repatriaciones en función del grado de satisfacción de las demandas españolas. Para el gobierno francés el centro de la cuestión estaba en asegurar la neutralidad española en caso de conflicto; para el español, en asegurar la devolución de los bienes exportados por los republicanos, de un nada desdeñable valor.

La interpretación que se dio de los acuerdos Jordana-Bérard, se movió por ambas partes dentro de una calculada ambigüedad, dando lugar a conflictos e infinidad de notas verbales. La actitud del gobierno francés de tolerar una oposición antifranquista en su territorio, de signo no comunista, era considerado por Madrid y por su embajador Lequerica una transgresión de los acuerdos de febrero, que ocupó a éste en numerosas protestas y conversaciones con autoridades francesas ${ }^{21}$; se hacia también objeto de denuncia el hecho de que no se devolviese la totalidad de lo exportado a Francia, incluido el material militar que permanecia retenido ante el temor, expresado en ciertos circulos franceses, de que en algún momento llegase a ser utilizado en una eventual agresión.

El gobierno francés por su parte, alegaba que no se habia liberado a los prisioneros franceses de las Brigadas Internacionales, no se habian sufragado los gastos ocasionados por los refugiados, se reavituallaba a los submarinos alemanes en puertos españoles, se concentraban tropas en el Marruecos español, y la prensa española se mostraba sistemáticamente hostil a la política francesa ${ }^{22}$.

Más adelante, la derrota de Francia haria cundir en el gobierno de Franco la idea de que se abrian más posibilidades que las resultantes de

AGA-AAEE. Caja 11.287, carpeta 3.". 4-VIII-39; también 20-XII-39.

"Cfr. AvILes FARRE, J., "L'ambassade de Lequerica et les relations hispano-françaises 1939-1944", Guerres mondiales et conflits contemporains. Paris, n. ${ }^{\circ} 158$, abril de 1990, págs. $65-78$. 
un entendimiento con el vencido. Quedaba asi justificado el temor existente en ciertos circulos franceses meses antes del desastre, fundado en que un cumplimiento exacto de los acuerdos Jordana-Bérard, significaria el reforzamiento de una potencia con muchas posibilidades de convertirse más adelante en beligerante contra Francia.

De esta desconfianza, saldrian beneficiados los refugiados, a quienes se evitó la pura y simple deportación a España, donde funcionaba a pleno rendimiento el aparato represivo franquista. Pero un sector de los mismos no por eso se libró de la represión en Francia, ya que el gobierno francés a partir de cierto momento abandonó la tolerancia para con los comunistas. Ya se mencionó más arriba que la organización del SERE no tuvo que sortear extraordinarias dificultades para su formación, y que incluso llegó a acreditarse ante el ministerio del Interior francés, y ello a pesar de las protestas de Lequerica. Esta tolerancia empieza a declinar en el momento en que la recién creada JARE es legalmente reconocida por Sarraut como única representación de la República Española.

Este cambio está estrechamente vinculado a la firma del pacto germano-soviético, que causó en Francia profunda conmoción. A resultas del mismo, comenzó la acción represiva contra los comunistas franceses, y las organizaciones vinculadas o afines, entre éstas supuestamente el SERE, que tuvo que sufrir varias intervenciones policiales, y la expulsión de parte de sus funcionarios de las proximidades de Paris. Pero la acción más importante tuvo lugar el 7 de diciembre de 1939, cuando por iniciativa del ministro de Justicia, Bonnet, la policía se incauta del dinero y de todos los archivos de sus locales parisienses, se bloquean numerosas cuentas corrientes, y se registran los domicilios de varias personas relacionadas con su aparato administrativo y de dirección, alegando indicios de delito ${ }^{23}$. A partir de este momento la existencia del SERE en Francia se irá haciendo progresivamente más difícil, si bien conseguirá subsistir en Paris hasta mayo de 1940 en que el nuevo ministro del Interior del gobierno Reynaud, Georges Mandel, cierra sus locales como medida insertada en un conjunto tendente a asegurar la neutralidad española en la guerra mundial. En junio, con los alemanes ya en París, la Gestapo se incauta de los locales del SERE, continuándose una actividad muy limitada con sede en Marsella. Para entonces, Negrín y Méndez Aspe alcanzan Londres, González Peña, México y Álvarez del Vayo, Estados Unidos.

${ }^{23}$ AGA-AAEE. Caja 11.287, carpeta 3. ${ }^{a}$, 6-XII-39. También 8-II-40. 


\section{CONCLUSIÓN}

Las consecuencias que trajo consigo la división de la cúpula dirigente republicana, tanto en el ámbito politico como en el asistencial - éste vinculado y en estrecha dependencia de aquél en el periodo aqui abarcado-, comprometieron seriamente la eficiencia de la politica de evacuación y asistencia, al fragmentar los recursos existentes. Se elude asi el planteamiento global que urgentemente requeria la atención a decenas de miles de personas desplazadas.

De mayor trascendencia, si cabe, para el futuro de España sería el hecho de que los republicanos en ningún momento supieron aunar criterios y voluntades para presentarse ante los aliados como una alternativa sólida y plausible al régimen de Franco, de manera que si los angloamericanos tenian ya buenas razones - desde su punto de vista- politicas y económicas para no desear un retorno de España a la legalidad republicana, los conflictos entre sus representantes les dieron un argumento más para considerar a Franco insustituible, llegados los tiempos de la guerra fría. De este modo, concluida la segunda guerra mundial, la falta de cohesión mostrada por los republicanos unida a las aludidas razones, permiten una progresiva normalización del Estado español en el campo internacional, proceso paralelo a la integración de los exiliados en los respectivos paises de adopción, que amortigua su militancia antifranquista, y que acaba con una reestructuración de la oposición, al centrarse en el interior de España el núcleo esencial de la misma, en tanto que la exterior cae en un progresivo anquilosamiento que reduce a las instituciones republicanas a un mero papel testimonial, como no tardaria en serlo el gobierno Giral (sustituto de Negrin en agosto de 1945), el gobierno Llopis (febrero de 1947), y más aún los dos gobiernos presididos por Albornoz hasta 1951, comienzo de una década en la que se producirá dicho relevo de la oposición exterior por la interior, más y mejor informada de los cambios de toda indole que se han verificado en España desde el fin de la guerra civil y consecuentemente, mejor preparada para encarar la resistencia al franquismo de la manera más factible.

\section{BIBLIOGRAFIA}

Abellan, J. L., et al., El exilio español de 1939. Madrid, Taurus, 1976. Tomos I y II.

AVILES FARRE. J., "L'ambassade de Lequerica et les relations hispano-françaises 1939-1944". Guerres mondiales et conflits contemporains. Paris, $n .{ }^{\circ} 158$, abril de 1990, págs. 65-78. 
Borras, J., Politicas de los exiliados españoles, 1944-1950. Chatillon-sous-Bagneux, Ruedo Ibérico, 1976.

Giral, F., Santidrián, P., La república en el exilio. Madrid, Ediciones 99, 1977.

Heine, H., La oposición politica al franquismo. Barcelona, Critica, 1983.

ROLLAND, D., «Aperçus sur la reemigration vers l'Amerique Latine des réfugies espagnols en France pendant les années de guerre. Politique des Etats et profil de réémigrants", en Milza, P., y Peschanski, D., Italiens et espagnols en France, 1938-1946. Colloque International. Paris. CNRS 28-29 de noviembre de 1991, págs. 51-94.

Rosal Diaz, A. del, Historia de la UGT de España en la emigración 1939-1950. Vol. 1. Barcelona, Grijalbo, 1978.

Soriano, A., Exodos. Historia oral del exilio republicano en Francia 1939-1945. Barcelona, Critica, 1989

TCACH, C., Clandestinidad y exilio. Reorganización del sindicato socialista, 1939-1953. Madrid, Editorial Pablo Iglesias, 1986.

Valle, J. M. del, Las instituciones de la República española en el exilio. Chatillon-sous-Bagneux, Ruedo Ibérico, 1976. 